Portland State University

PDXScholar

Winter 3-28-2019

\title{
The Influence of Hibernation Temperature on Deiodinase 2 in Red-Sided Garter Snakes (Thamnophis sirtalis parietalis)
}

Kalera Stratton

Portland State University

Follow this and additional works at: https://pdxscholar.library.pdx.edu/open_access_etds

Part of the Biology Commons

Let us know how access to this document benefits you.

Recommended Citation

Stratton, Kalera, "The Influence of Hibernation Temperature on Deiodinase 2 in Red-Sided Garter Snakes (Thamnophis sirtalis parietalis)" (2019). Dissertations and Theses. Paper 4865.

https://doi.org/10.15760/etd.6741

This Thesis is brought to you for free and open access. It has been accepted for inclusion in Dissertations and Theses by an authorized administrator of PDXScholar. Please contact us if we can make this document more accessible: pdxscholar@pdx.edu. 
The Influence of Hibernation Temperature on Deiodinase 2 in Red-Sided Garter Snakes (Thamnophis sirtalis parietalis)

by

Kalera Stratton

A thesis submitted in partial fulfillment of the requirements for the degree of

Master of Science

in Biology

Thesis Committee:

Deborah I. Lutterschmidt, Chair

Randy Zelick

Radhika Reddy

Bradley Buckley

Portland State University 2019 
(C) 2019 Kalera Stratton 


\begin{abstract}
Environmental cues such as day length and temperature contribute to timing of biological rhythms in seasonal breeders. Life-history transitions such as spring emergence from hibernation, migration, or mating must be coordinated with environmental conditions or survival is compromised. Therefore, there must be chemical signaling pathways in the brain that transduce seasonally-changing sensory inputs into signals that initiate a hormonal cascade, culminating in reproductive behavior. The relative importance of environmental cues to
\end{abstract} reproductive timing varies with species, time of year, and sex, and the mechanisms driving these differences remain unknown. The role of photoperiod in regulating reproductive behavior has been explored in birds and mammals, but much less is known about the role of so-called supplementary cues such as temperature, which is crucial in the timing of ectotherm reproduction. This is a critical gap in our knowledge, because shifts in seasonal temperatures due to climate change could create a mismatch between peak reproductive behavior and resources necessary for gestation and offspring survival. Deiodinase 2 (DIO2) enzyme is a critical component of the pathway that mediates reproduction in photoperiod-activated seasonal breeders, but whether deiodinase 2 is sensitive to seasonal changes in environmental temperature is unknown. In this study, we used an ectothermic vertebrate known to be a temperature-activated seasonal breeder, the red-sided garter snake (Thamnophis sirtalis parietalis), to investigate changes in hypothalamic DIO2 in response to hibernation at $4^{\circ} \mathrm{C}$ and $12^{\circ} \mathrm{C}$. We captured male and female snakes in Manitoba, Canada as they returned to their winter den site from summer 
feeding grounds. Snakes were hibernated in complete darkness at either $4{ }^{\circ} \mathrm{C}$ or 12 ${ }^{\circ} \mathrm{C}$ for up to 16 weeks. A subset of each sex and temperature group were euthanized at intervals, and the brains collected and processed for DIO2 immunohistochemistry. DIO2-specific staining was found in the anterior hypothalamus, in the periventricular hypothalamic nucleus and ventral pre-optic area, along the longitudinally central region of the olfactory tract, in the bed nucleus of the stria terminalis, caudally in the cortex and optic tectum, and in the lateral septal nucleus. DIO2-stained area in the anterior hypothalamus was quantified. Male T. sirtalis in both the $4{ }^{\circ} \mathrm{C}$ and $12{ }^{\circ} \mathrm{C}$ groups were found to have an increase in DIO2specific staining in the anterior hypothalamus after 8 weeks in hibernation. Female T. sirtalis were found to have an increase in DI02-specific staining in the anterior hypothalamus after 8 weeks in the $12{ }^{\circ} \mathrm{C}$ group only. These findings shed light on the neuroendocrine pathway through which environmental cues other than photoperiod influence the timing of seasonal reproduction, and support the hypothesis that at least some components of this pathway are conserved across seasonal breeders. 


\section{Acknowledgements}

I want to thank my advisor Deborah Lutterschmidt for supporting me on my bumpy journey to becoming a researcher through thick and thin, as well as my committee members Randy Zelick, Radhika Reddy, and Bradley Buckley for providing invaluable support and acting as my sounding board through the inevitable frustrations on the pathway to my Master of Science. I also want to thank Suzanne Estes for making the initial connection between her hopeful would-be neuroscientist LSAMP scholar and her snake-brain-researching colleague, and a special thanks to Suzy Renn at Reed College for letting me use her cryostat to finish processing tissues when our compressor went out. My amazing labmates Rachel Wilson and Treven Winters have my undying friendship and gratitude for being there listening, brainstorming, answering questions, staying up all night helping with assays, commiserating in the hard times, and, especially, celebrating the triumphs. We have grown so much together! Thanks also to Ashley Maine Lucas for training me in the lab and the field, always with humor and positivity. Cat Dayger and Jessica Hebert have my profound gratitude for the moral support and wisdom they provided. Many thanks to the Ford Family Foundation for providing me with the crucial financial support that allowed me to undertake this endeavor while supporting a family, and to the McNair Scholars Program for helping this budding scientist waive graduate program application fees. Finally, I want to thank my family for bearing with me through late nights and long days; thank you, Jules Ashley, Adam Stratton, Pista Szabo, Killian Szabo, and, always in memory, Sam Ashley. 


\section{Table of Contents}

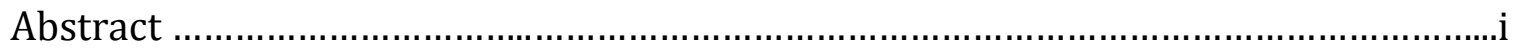

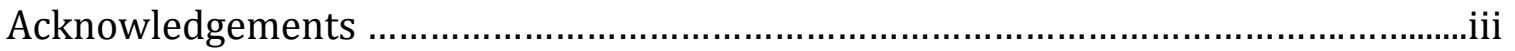

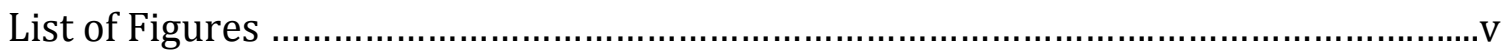

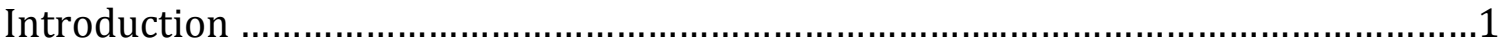

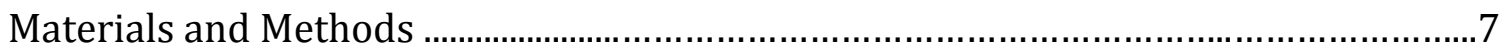

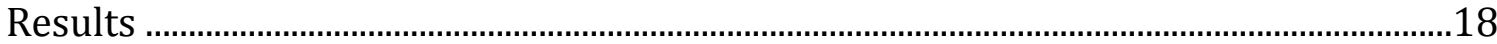

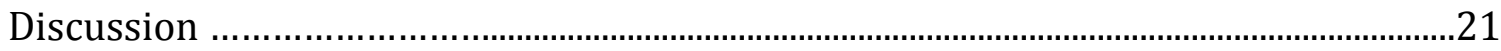

Bibliography 


\section{List of Figures}

Figure 1. Diagram of the Hypothalamus-Pituitary-Gonadal axis

Figure 2. Example photomicrographs of sagittal sections of T. sirtalis brains showing different degrees of staining.

Figure 3. Screenshot of batch process window, showing script for setting the scale and converting the image files to 8-bit grayscale.

Figure 4. Screenshot of the Threshold tool in use.

Figure 5. Example photomicrographs from deiodinase II (DIO2) antiserum preadsorption tests.

Figure 6. The sum of DIO2-specific staining in the hypothalamus of female T. sirtalis during hibernation at $4^{\circ} \mathrm{C}$ or $12^{\circ} \mathrm{C}$.

Figure 7. The sum of DIO2-specific staining in the hypothalamus of male T. sirtalis during hibernation at $4^{\circ} \mathrm{C}$ or $12^{\circ} \mathrm{C}$. 


\section{Introduction}

Environmental cues such as day length and temperature contribute to timing of biological rhythms in seasonal breeders (Moore et al. 1984; Dawson et al., 2001; Woodfall et al.,1994). Life-history transitions such as spring emergence from hibernation, migration, or mating must be coordinated with environmental conditions or survival is compromised. For example, emerging from hibernation before the end of winter, moving from one feeding ground to another before food sources are ready, or giving birth to offspring when food sources are suboptimal, could all mean death for an organism or its offspring. Because animals that reproduce in a specific season each year must coordinate the timing of reproduction with the environmental conditions in which they live, it makes sense that they use physical cues from the environment around them to indicate when it is appropriate to transition to a reproductively active state. Therefore, there must be chemical signaling pathways in the brain that transduce seasonally-changing sensory inputs into cues that initiate a hormonal cascade, culminating in reproductive behavior.

The relative importance of environmental cues to reproductive timing varies with species, time of year, and sex, and the mechanisms driving these differences remain unknown. Most of the research into the mechanisms that regulate differences in the timing of seasonal reproduction is relatively recent, and there is much yet to be discovered. For some organisms, day length, or photoperiod, is the primary cue that drives the shift to reproductive behavior. For others, temperature or social cues are the primary activators of reproductive behavior. In some bird 
species there is a high level of variability between sexes in how much a given cue affects reproductive behavior (Ball \& Ketterson, 2008).

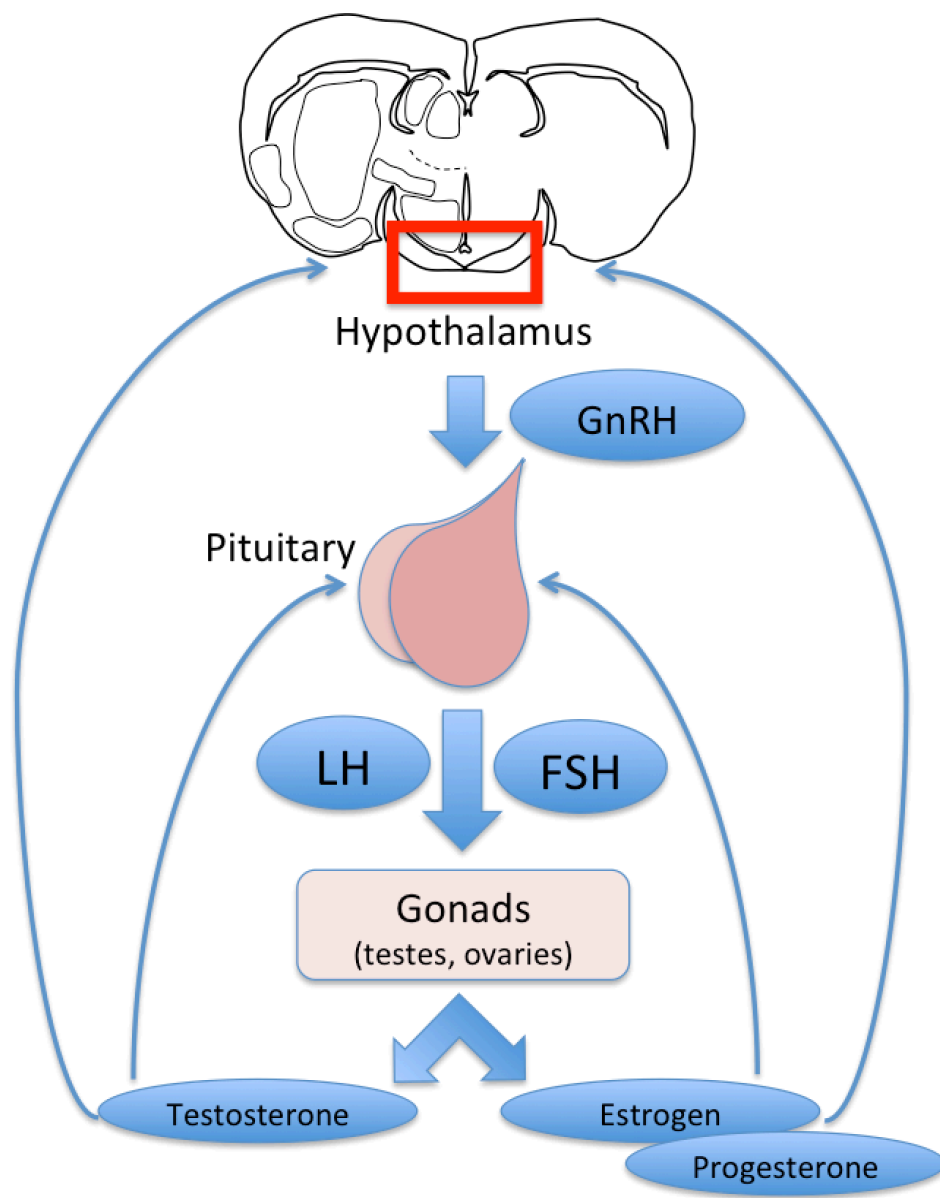

Figure 1. Diagram of the Hypothalamic-Pituitary-Gonadal axis. GnRH from the hypothalamus signals the pituitary to release gonadotropins LH and FSH, which in turn signal the gonads to release sex steroids. Feedback loops to the pituitary and hypothalamus help regulate sex steroid levels.

Seasonal changes in reproductive physiology are regulated by gonadotropin releasing hormone (GnRH) (Cho et al., 1998). The hypothalamic-pituitary-gonadal (HPG) axis (Fig. 1) is the core regulatory pathway through which reproduction is modulated. Specifically, enzymes produced in the hypothalamus have a regulatory effect on GnRH, which stimulates reproductive changes in vertebrates by signaling 
the pituitary to release the gonadotropic hormones luteinizing hormone (LH) and follicle stimulating hormone (FSH). These gonadotropins in turn stimulate sexspecific increases in sex steroid hormones in the gonads, including estrogen, progesterone, and testosterone, and triggering gametogenesis in the gonads (Nakane \& Yoshimura, 2014). Though much remains to be discovered, relatively recent research sheds some light on the less well-understood influence of GnRH in reproductive behavior.

Seasonal changes in GnRH in the brain are mediated by the thyroid hormone triiodothyronine $\left(\mathrm{T}_{3}\right)$, which induces synthesis and release of GnRH. Researchers have learned a good deal about how GnRH is regulated in animals that use photoperiod as the primary environmental cue for reproduction: $\mathrm{T}_{3}$ stimulates release of $\mathrm{GnRH}$, and $\mathrm{T}_{3}$ is regulated by deiodinase enzymes produced in tanycytes along the third ventricle of the brain (Duarte-Guterman et al., 2014; Lewis \& Ebling 2017; Watanabe et al., 2004). Deiodinase 2 (DIO2) enzyme is a critical component of the pathway mediating synthesis of GnRH in photoperiod-activated seasonal breeders (Köhrle, 1999). Deiodinase 2 converts less-bioactive thyroid hormone thyroxine $\left(\mathrm{T}_{4}\right)$ to highly bioactive $\mathrm{T}_{3}$, and $\mathrm{T}_{3}$ stimulates synthesis \& release of $\mathrm{GnRH}$. Deiodinase 3 inactivates $T_{3}$, so deiodinase 2 and 3 acting in combination serve as a potent regulator of $\mathrm{GnRH}$ and reproduction. It has been found that these two deiodinases are modulated by environmental cues to facilitate accumulation of $\mathrm{T}_{3}$ in the brain, which increases GnRH and in turn mediates the seasonal brain changes needed for reproductive behavior (de Miera et al., 2014). This pathway has been studied in mammals, birds, and fish, in which it has been found to be responsive to 
photoperiod cues (Prendergast et al., 2013; MacDougall-Shackleton et al., 2001; Nakane et al., 2013).

While most seasonal breeders, such as hamsters and quail, use photoperiod as their primary environmental cue, many use other environmental cues, such as temperature, social signals, food availability, precipitation, or water conductivity to supplement their primary cue (Kirschbaum, 1987; Perfito, 2004). The role of photoperiod in regulating reproductive behavior has been explored in birds and mammals, but much less is known about the role of so-called supplementary cues such as temperature, which is crucial in the timing of ectotherm reproduction (Licht, 1972). This is a critical gap in our knowledge, because shifts in seasonal temperatures due to climate change could create a mismatch between peak reproductive behavior and resources necessary for gestation and offspring survival, such as food sources (Bronson, 2009). This is a topic of increasing concern as climate change alters the timing of seasonal temperature changes, particularly in temperate regions (McLean \& Wilson, 2011).

It is notable that the majority of the animal models used thus far to examine the reproductive timing pathway have been endotherms. One of the challenges of studying the effects of temperature on reproductive timing is that the warm-blooded animals most commonly used for neuroendocrine laboratory experiments can physiologically regulate their own temperatures, making it difficult to isolate the effects of environmental temperature. However, ectotherms must rely primarily on behavior for thermoregulation, making an ectotherm an excellent choice of organism for studying the relationship between temperature and this mechanistic pathway. It is the aim of 
this research to identify the impact of temperature on the deidodinase 2 enzyme in the GnRH pathway of a temperature-activated seasonal breeder. In doing so, this research will also identify whether reptiles share the same mechanisms that activate seasonal breeding in other vertebrates. If this is the case, it would provide supporting evidence that these mechanisms are conserved among vertebrates.

Northern populations of red-sided garter snakes, Thamnophis sirtalis parietalis, are an ideal animal model for studying this reproductive timing pathway. One advantage of using these animals is that not only are they ectotherms, but their seasonal reproduction is exclusively regulated by the so-called "supplemental" environmental cue of temperature (e.g., Whittier et al., 1987), making them an ideal organism for investigating this pathway. A great deal of research has been done with these snakes, so we know their typical hibernation temperatures in the wild are as low as $1^{\circ} \mathrm{C}$ (Lutterschmidt et al. 2006). They also have robustly stereotyped mating behaviors, making it easy to assess behavior and correlate it to biological markers such as neurohormone and enzyme levels in the brain. Not least, they are numerous in the wild and can be collected in the numbers needed for this research without damage to the wild population. In combination, these characteristics make them an optimal choice of organism for answering the question of whether temperature influences DIO2 in the same way photoperiod does in other animals.

Our hypothesis is that production of deiodinase 2 in the brain is temperaturesensitive, and that not only will the duration of hibernation correlate with an increase in deiodinase 2 levels in the brain, but that the increase in deiodinase 2 will be greater at $4^{\circ} \mathrm{C}$ than it will be at $12^{\circ} \mathrm{C}$. To test this hypothesis, we hibernated male and female 
red-sided garter snakes at $4^{\circ} \mathrm{C}$ or $12^{\circ} \mathrm{C}$ similar to previous studies in this species. We took baseline tissue samples consisting of whole brains from each group immediately pre-hibernation, as well as after 4,8 , and 16 weeks of hibernation. The samples were processed for immunohistochemistry, a method that preserves information about the location of our peptide of interest, to quantify changes in deiodinase 2 staining in the hypothalamus. We used the resulting immunostaining as a proxy for directly measuring DIO2, ie. when DIO2-specific immunostaining in tissue increases, we expect that DIO2 has increased.

The implications of this research are multifold. First, it will utilize a reptile model to elucidate the pathway by which supplementary environmental cues are transduced to affect reproductive behavior. Second, by studying this in an animal that shares a common ancestor with both birds and mammals, it will test the hypothesis that these pathways are evolutionarily conserved across vertebrates. Third, it helps ecologists and conservationists make predictions about ways in which climate change may affect seasonally-reproducing animals. Finally, basic scientific research that expands our body of knowledge often has applications far beyond those we are able to anticipate from our limited temporal vantage point, and this knowledge helps build the foundation for future discovery and innovation. 


\section{Methods and Materials}

These experiments were conducted in the laboratory at Portland State University with red-sided garter snakes (Thamnophis sirtalis parietalis) collected from a field site in Inwood, Manitoba, Canada. All protocols were approved by PSU's Institutional Animal Care and Use Committee and performed under the authority of a Manitoba Department of Sustainable Development Scientific Wildlife Collecting permit.

\section{Field collection}

From 16-18 September 2016, we captured snakes by hand as they returned to their winter den site from summer feeding grounds. Animals were segregated by sex and housed in outdoor arenas with open tops and 61-cm diameter; water was provided ad libitum.

\section{Captive care}

After capture, 84 males and 40 females (n=124 total) were randomly selected to be included in this experiment. Each animal was weighed, measured, and assigned a unique number with which to track the animal throughout this experiment. Using a code, the numbers were clipped into the ventral scales of each animal using a corneoscleral punch.

Animals were transported to PSU in pillowcases. Upon arrival at PSU on 21 September, animals were housed in groups of 4 (females) or 8 (males) in 40-liter aquaria in environmental chambers and acclimated to autumn-like environmental 
conditions (11:13 h L:D photoperiod, $18: 12^{\circ} \mathrm{C}$ thermoperiod) for 4 weeks. Water was provided ad libitum.

Beginning on 20 October, animals were hibernated in complete darkness (0:24 h L:D photoperiod) in humidity-controlled environmental chambers at either $4{ }^{\circ} \mathrm{C}$ or $12{ }^{\circ} \mathrm{C}$ for up to 16 weeks. Snakes were randomly assigned to each temperature treatment and sampling period. Water was provided ad libitum for the duration of hibernation. For tissue sampling, a subset of 12 males was euthanized at $0,4,8$, and 16 weeks in hibernation, a subset of 8 females was euthanized at 0,8 , and 16 weeks in hibernation, and the brains collected for DIO2 immunohistochemistry.

\section{Tissue preparation}

Snakes were euthanized with an overdose of sodium Brevital and the brains collected for immunohistochemistry. The brains were fixed via immersion in $4 \%$ paraformaldehyde in $0.1 \mathrm{M}$ phosphate buffer, $\mathrm{pH} 7.2$, at $4{ }^{\circ} \mathrm{C}$ for 18 hours. They were then transferred to $0.1 \mathrm{M}$ phosphate buffer and stored at $4{ }^{\circ} \mathrm{C}$.

For the purposes of a second, independent part of this project examining temperature-induced changes in the pituitary gland, we preserved the structural integrity of the pituitary gland during cryosectioning by leaving the ventral portion of the skull intact during tissue dissection. We then decalcified the intact ventral skull by incubating the tissues in a minimum of 15 volumes of $14 \%$ ethylenediaminetetraacetic acid (EDTA) solution ( $\mathrm{pH}$ 7.2) for 4 days; the solution 
was changed daily. Test assays confirmed that DIO2-specific binding was minimally affected by this EDTA treatment (data not shown).

We prepared the brains for sectioning by immersing them in $30 \%$ sucrose solution until saturated, then freezing in cryogenic media in a $2.5 \times 2.5 \times 0.6 \mathrm{~cm}$ plastic mold. We chilled Isopentane (2-methylbutane) in a $10 \mathrm{~cm}$ stainless steel bowl by nesting the bowl approximately $5 \mathrm{~cm}$ into crushed dry ice. We wrote each animal number on a plastic mold with permanent marker, filled the mold with cryogenic media, placed the brain in the media, then suspended the bottom of the mold in the isopentane. The brains were thoroughly frozen after 3 minutes in the chilled isopentane, after which we wrapped them in Parafilm followed by aluminum foil. The frozen brains were then stored at $-80^{\circ} \mathrm{C}$. Brains were sectioned on a cryostat (Leica 3050S) into 4 alternate series of $25-\mu \mathrm{m}$ sagittal slices. The slices were thaw-mounted onto slides (Fisherbrand Superfrost Plus) coated with a gelatin substrate. These brain tissues were then stored at $-20^{\circ} \mathrm{C}$ until they were processed for immunohistochemistry.

\section{Immunohistochemistry}

We examined differences in deiodinase 2 among groups via immunohistochemistry for deiodinase 2 enzyme within the hypothalamus. All slides were processed in a single assay following the protocols described by Lutterschmidt and Maine (2014). Slides containing the region of interest (medial hypothalamus) were defrosted and dried on a slide warmer at $50{ }^{\circ} \mathrm{C}$ for at least $30 \mathrm{~min}$, after which the tissues were outlined with a hydrophobic barrier (Liquid Blocker - Super Pap 
Pen; Electron Microscopy Sciences, Hatfield, Pa., USA). The slide-mounted tissues were then incubated in $4 \%$ paraformaldehyde in $0.1 \mathrm{M}$ phosphate-buffered saline (PBS; pH 7.4) for 5 minutes to ensure adherence of tissue to slides. Slides were washed 3 times for 5 min per wash with 0.1 M PBS, followed by fixative neutralization with $0.1 \%$ sodium borohydride $(\mathrm{pH} 8.5)$ for $20 \mathrm{~min}$. The slides were washed again in PBS $(3 \times 5 \mathrm{~min})$. To reduce nonspecific background staining from unwanted endogenous peroxidase reactivity with the 3,3'-Diaminobenzidine (DAB) used in the final staining step, endogenous peroxidase activity was quenched with 1\% hydrogen peroxide in 0.1 M PBS for 30 min. The slides were washed in PBS $(2 \times$ $5 \mathrm{~min}$ ) followed by PBS with $0.3 \%$ Triton X (PBS-T; $1 \times 5 \mathrm{~min}$ ) and then incubated for 60 min in PBS-T containing 10\% normal horse serum (item H1270, SigmaAldrich Co.) and 10\% Avidin (item SP-2001, Vector Labs, Burlingame, CA 94010, USA) to reduce nonspecific binding. DIO2 immunoreactivity was examined using a goat anti-DIO2 antiserum (item ab-77481; Abcam, Cambridge MA 02139-1517, USA) at a dilution of 1: 2,000 in PBS-T containing 10\% normal horse serum (item G676, Sigma-Aldrich Co.) and 10\% biotin (item SP-2001, Vector Labs). Sections were coverslipped with parafilm and incubated with the primary antibody for $48 \mathrm{~h}$ at $4{ }^{\circ} \mathrm{C}$ in a humid chamber. After primary antibody incubation the coverslips were removed in PBS and the slides washed in PBS $(2 \times 5 \mathrm{~min})$ followed by PBS-T $(1 \times 5$ $\min$ ). The primary antibody signal was amplified by incubation for 60 min with biotinylated horse anti-goat secondary antibody (item BA-9500; Vector Labs) diluted 1: 400 in 0.1 M PBS-T. The slides were washed in PBS $(2 \times 5 \mathrm{~min})$ followed by PBS-T $(1 \times 5 \mathrm{~min})$. Tissues were incubated for $60 \mathrm{~min}$ in avidin conjugated to 
horseradish peroxidase (Elite ABC peroxidase kit; Vector Labs) to complete the biotin-avidin- HRP amplification step, and rinsed in PBS $(2 \times 5 \mathrm{~min})$ followed by PBS-T $(1 \times 5 \mathrm{~min})$. The specific antibody signal was further amplified by incubation with $100 \mu \mathrm{L}$ biotinylated tyramide solution (Item SAT700; PerkinElmer, Waltham, MA 02451, USA) at a dilution of 1:50 for 60 min; slides were coverslipped with Parafilm during the incubation period and then washed in PBS $(2 \times 5 \mathrm{~min})$ followed by PBS-T $(1 \times 5 \mathrm{~min})$. The final amplification step was a second incubation with 400 $\mu \mathrm{L}$ avidin- horseradish peroxidase conjugate (Elite ABC peroxidase kit; Vector Labs) for $60 \mathrm{~min}$. The slides were washed in PBS $(2 \times 5 \mathrm{~min})$ followed by PBS-T $(1 \times 5$ min). Primary antibody binding was visualized using $0.25 \mathrm{mg} / \mathrm{ml}$ 3,3'Diaminobenzidine (DAB) (item 0430-5G; BioExpress, Kaysville, Utah, USA) in 0.2\% hydrogen peroxide in $0.05 \mathrm{M}$ Tris- $\mathrm{HCl}$ buffer ( $\mathrm{pH}$ 7.2). The reaction was terminated by immersion in nanopure $\mathrm{H}_{2} \mathrm{O}(3 \times 5 \mathrm{~min})$. Tissues were dehydrated in a graded ethanol series (70, 85, 95, 100\%, 2 min ea.), cleared with Citrasolv (Fisher Scientific, Pittsburgh, Pa., USA), and covered with Permount and coverslips.

To confirm that the staining was due to primary antibody specificity to DIO2 in T. sirtalis, we performed a preadsorption assay. Prior to immunohistochemistry, we incubated diluted DIO2 antibody $(1: 2000)$ overnight at $4{ }^{\circ} \mathrm{C}$ with synthetic DIO2 peptide (EVKKHQNQEDRC) (item 131396, Abcam,) at a concentration of $50 \mu \mathrm{g} / \mathrm{mL}$. We used the same antibody solution with no peptide for a control, using slides consisting of alternating tissue sections taken from the same animals. 


\section{Immunoreactivity quantification}

Animals were coded to ensure that the observer was blind to the treatment group of each animal. Because individual cell bodies were typically not distinguishable based on immunoreactive staining, cell counts would not have yielded an accurate representation of DIO2 presence; therefore, we quantified DIO2specific staining by measuring and summing the area of the staining across the anterior hypothalamus. After the deiodinase-producing brain cells were immunohistochemically stained to render them distinct from the background tissue, we photographed the region of interest in the hypothalamus at 200x using an Olympus BX40 microscope with a QIClick digital camera and QImaging software (QImaging; Surrey, B.C., Canada). We endeavored to maintain consistent light balance for all photos, but some variation was unavoidable, as it was not feasible to photograph all the sections in the same session. Manual thresholding of the digital area selection was required to compensate for variation in background and specific staining, and this also served to adjust for the minor differences in light balance across photos. This manual thresholding process was validated by taking repeated measurements from the same sections and comparing the results for similarity; only inconsequential differences were found between repeated measurements of the same sections. Because of the necessary subjectivity of manual thresholding, all of the DIO2-stained area data were collected by the same individual in order to avoid inter-observer variation. Photography was spread over the span of one week.

We identified an area of the anterior hypothalamus directly superior to the pituitary as our target region of interest (ROI) for assessing area of DIO2 staining in 
a sagittally-sectioned brain. For consistency, the area was photographed at 200x starting when the pituitary sections began to take on a distinctive almond shape, indicating sections were leaving the lateral margin and approaching the midline, and ceasing on the other side of the midline when the pituitary once again reduced to a smaller, more circular shape, indicating that sections were nearing the lateral margins. This approach helped ensure that we included every section that represented our region of interest. The inferior margin of the hypothalamus served as the lower boundary for the photomicrographs. The area of stained tissue in each section of the hypothalamus was determined using the thresholding tool in ImageJ software to select all areas that appeared visibly darker than the background staining of that tissue section to such a degree that we deemed them to be specific staining. Because levels of background and specific staining varied considerably from slide to slide, and somewhat from section to section, this process required each image to be individually thresholded and measured.

In order to avoid artificial inflation or deflation of the stained area, we developed specific parameters around how to assess animals with very little staining, medium staining, and a great deal of staining (fig. 2). For animals with little to no specific staining (mean staining across all measured sections $<1000 \mu \mathrm{m}^{2}$ ), we measured 2-5 medial sagittal sections that we knew should exhibit DIO2-specific staining. In animals with moderate staining (mean staining across all measured sections $1000 \mu \mathrm{m}^{2}$ to $3000 \mu \mathrm{m}^{2}$ ), we measured all sections with staining that was visually distinguishable from background $(\min 2, \max 8)$. In animals with heavy staining (mean staining across all measured sections $>3000 \mu \mathrm{m}^{2}$ ), we measured all 
sections with staining that was visually distinguishable from background (min 2, max 9), but with the additional condition of restricting measurement of the lateralmost sections to those with staining that was at least $16 \%$ of the maximum staining within that same animal. This additional condition served to set firm boundaries on the sections measured and avoid artificially inflating the sum of the stained area. We acknowledge that this approach was highly conservative, and may have artificially decreased the magnitude of the between-groups differences we found.
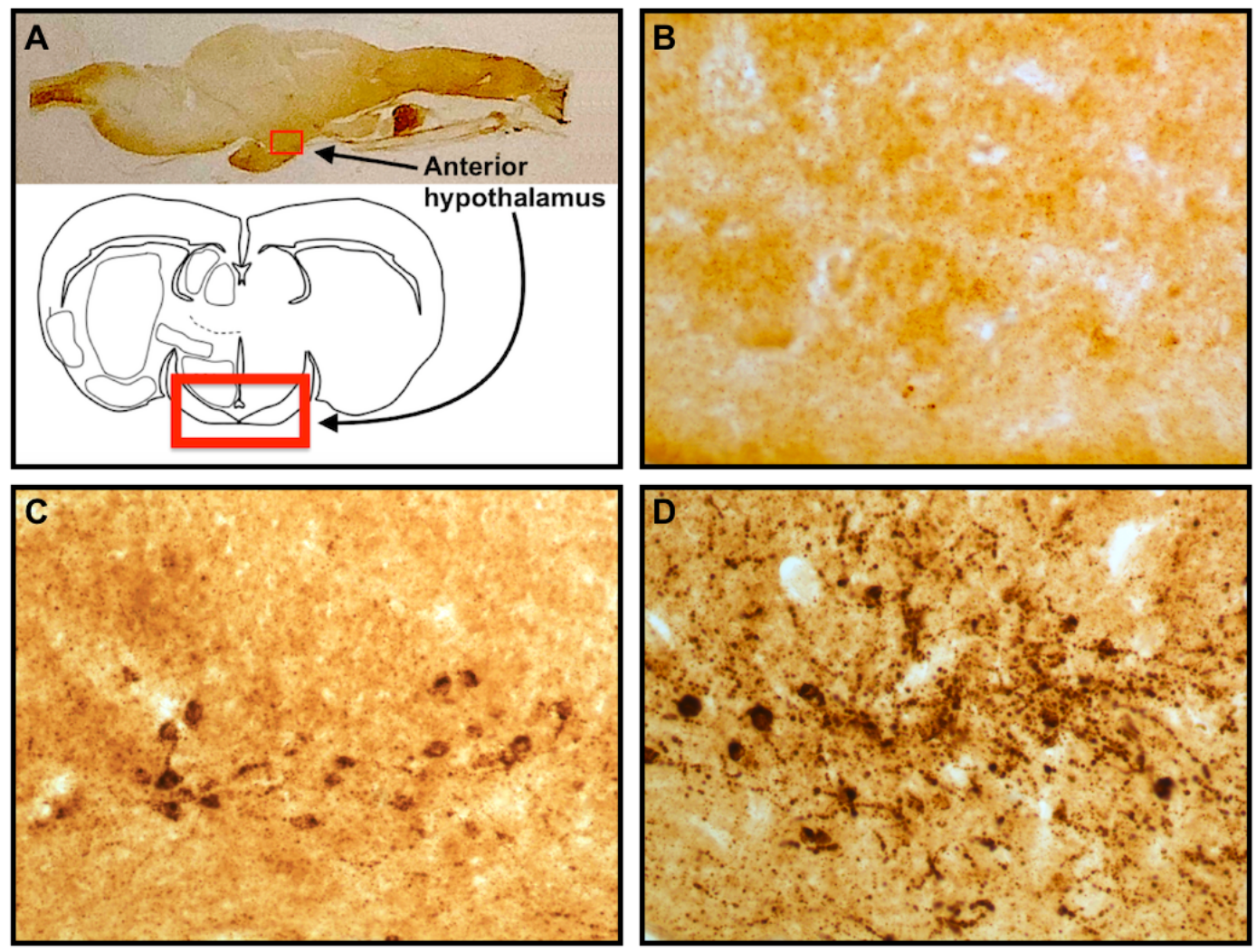

Figure 2. Example photomicrographs of sagittal sections of $T$ sirtalis brains demonstrating (A) anatomical location of anterior hypothalamus within the brain, (B) light specific staining, (C) moderate specific staining, and (D) heavy specific staining for DIO2. Photomicrographs were taken at 200x magnification.

Each photograph was uploaded into ImageJ software (Fiji 2 download, ImageJ version 2.0.0-rc-68/1.52e). Before beginning data collection, we used the Analyze $>$ Set Scale menu function in ImageJ to calibrate the images for the correct 
microscope magnification. For these images, the calibration for 200x was 3.15 pixels $=1 \mu \mathrm{m}$. We then converted all images to 8-bit 256-grayscale images using the Image $>$ Type $>8$-bit menu function, to permit the use of the thresholding tool based on pixel density alone without having to adjust for the additional variables of color thresholding.

To convert all images to 8-bit and set scale at the same time, we selected Process $>$ Batch $>$ Macro, selected origin and destination folders, and typed the following code into the macro box (fig. 3):

run("8-bit");

run("Set Scale...", "distance=3.15 known=1 pixel=1 unit= $\mu \mathrm{m} ")$;

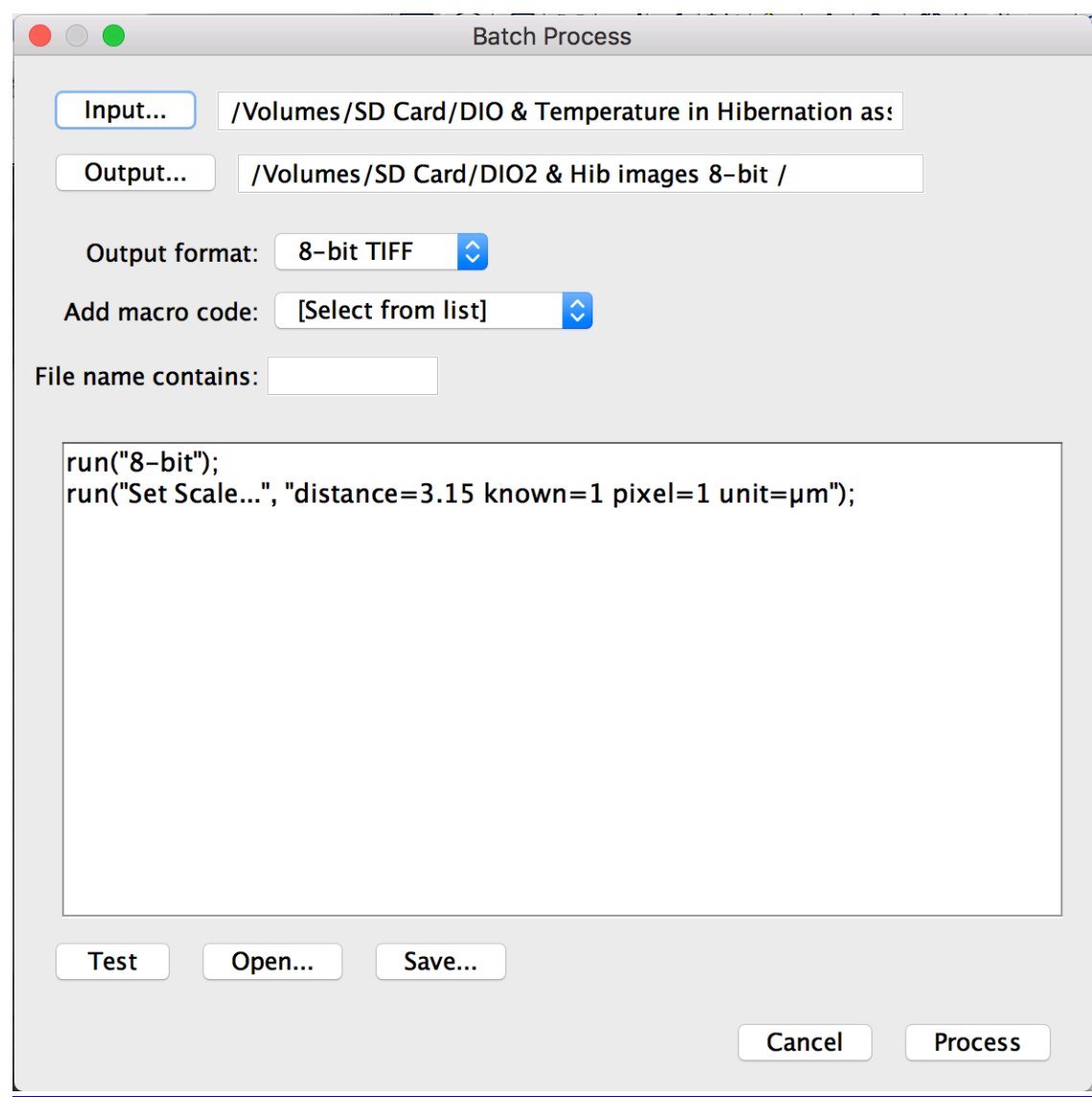

Figure 3. Screenshot of batch process window, showing script for setting the scale and converting the image files to 8-bit grayscale. 
Once the images were calibrated and converted to 8-bit, we began collecting data. For this, we opened a target image and selected Image>Adjust>Threshold. A window with a histogram and two slider tools opened. We moved the bottom slider until all the area that we visually determined was specific staining was captured in red (fig. 4). We then clicked "Apply".

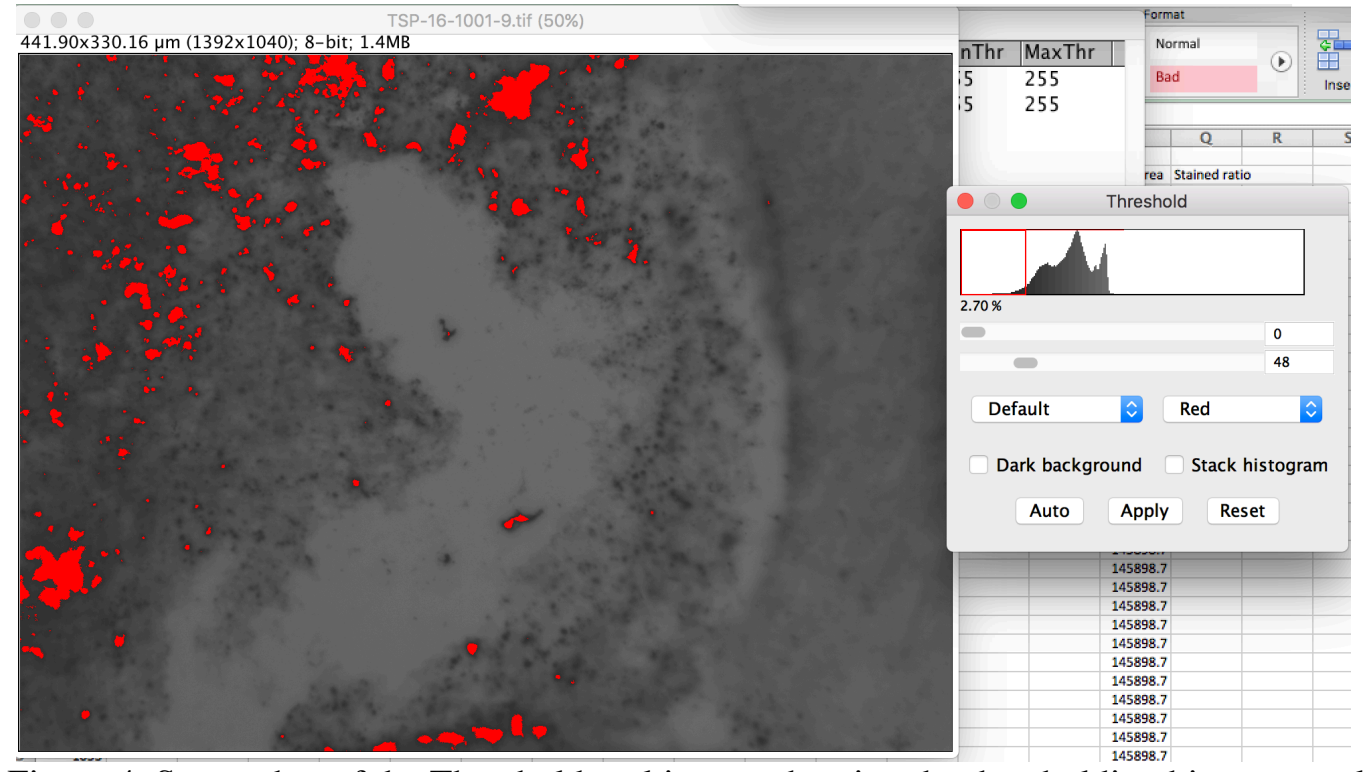

Figure 4. Screenshot of the Threshold tool in use, showing the thresholding histogram, slider tools, and grayscale image, with pixels that are above the selected threshold highlighted in red.

After these selections were applied, the image turned from grayscale to black and white, with the selected areas shown in black, and background shown in white. We then selected Analyze>Measure, and our measured area appeared in the "Results" box. We saved the results as an Excel file, and copy-pasted the measured stained area from each section into our final master Excel spreadsheet. We calculated the sum of the measured stained area within the medial hypothalamus of each animal to quantify the DIO2-specific staining. 


\section{Statistical Analysis}

Male and female T. sirtalis are sexually dimorphic, with females having an overall larger body size and proportionally larger brain size that could reasonably be expected to translate to a larger DIO2 stained area. Thus, we analyzed these groups separately. For females, differences among groups were analyzed with a two-way analysis of variance, General Linear Model. We adjusted for skewness by transforming the data using the natural log. The sum of the stained area for each animal was the dependent variable, and temperature and duration of hibernation were the between-subjects factors. This transformation of the data met the assumptions for normality (Shapiro-Wilk $\mathrm{P}=0.143$ ) and Equal Variance $(\mathrm{P}=0.635)$. Significant main effects were further examined with an all-pairwise multiple comparisons procedure (Student-Newman-Keuls Method).

For males, differences among groups were assessed using the natural log of the sum of the stained area measurements from each animal as the dependent variable. Because data transformation could not correct for deviations from normality and equal variance, we used the non-parametric Scheirer-Ray-Hare extension of the Kruskal-Wallis ANOVA on ranks. $\mathrm{H}$ and $\mathrm{P}$ values were then calculated manually from the mean squares and sum of squares data included in the ANOVA table. Significant main effects were further examined with a non-parametric multiple comparisons test. 


\section{Results}

Preadsorption results confirmed that our antibody staining is specific for DIO2: staining was reduced to background levels with preadsorption of the antibodies by incubating the DIO2 antibody solution with an excess amount of DIO2 peptide prior to proceeding with immunohistochemistry (fig. 5).

We found DIO2-specific staining in the anterior hypothalamus, in the periventricular hypothalamic nucleus and ventral pre-optic area, along the longitudinally central region of the olfactory tract, in the bed nucleus of the stria terminalis, caudally in the cortex and optic tectum, and in the lateral septal nucleus. Other than our examination of the anterior hypothalamus, the meaning of DIO2 presence in these areas remains unknown. We selected the stained area in the anterior hypothalamus for quantification purposes, as this population of DIO2producing cells is most directly relevant to our hypothesis about temperatureinduced changes in DIO2 regulating GnRH and seasonal reproduction.

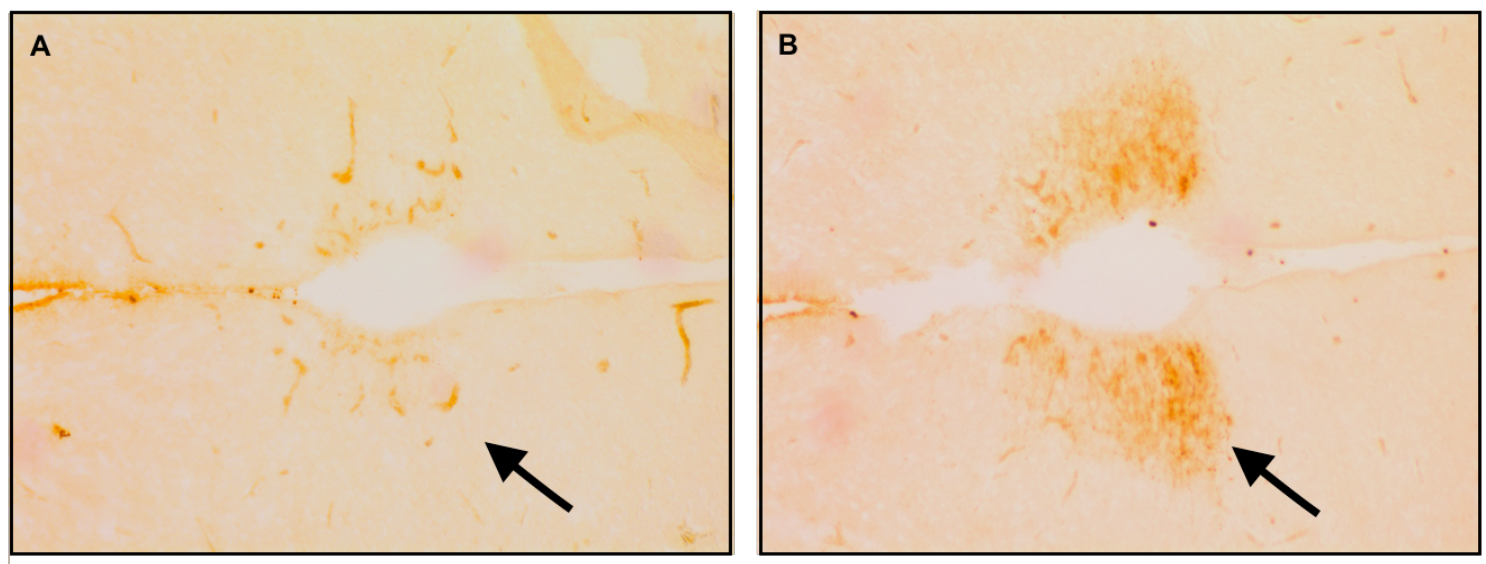

Figure 5. Example photomicrographs from deiodinase II (DIO2) antiserum preadsorption tests in red-sided garter snakes ( $T$. sirtalis). Immunoreactive staining is shown following preadsorption of DIO2 antibody (diluted 1:2000) with (A) $50 \mu \mathrm{g}$ or (B) $0 \mu \mathrm{g}$ DIO2 peptide per milliliter of antibody solution. 
Hibernation temperature had a significant effect on DIO2-immunoreactive stained area $\left(\mu \mathrm{m}^{2}\right)$ in the hypothalamus of female $T$. sirtalis $\left(\mathrm{F}_{1,39}=7.184, \mathrm{P}=0.011\right)$ (fig. 6). We found that the area of staining was greater in animals hibernated at $12^{\circ} \mathrm{C}$ than in animals hibernated at $4^{\circ} \mathrm{C}$. Neither the duration of hibernation $\left(\mathrm{F}_{2,39}=1.861\right.$, $\mathrm{P}=0.171)$ nor the interaction term $\left(\mathrm{F}_{2,39}=1.881, \mathrm{P}=0.168\right)$ significantly affected DIO2stained area $\left(\mu \mathrm{m}^{2}\right)$ in the hypothalamus of female red-sided garter snakes.

Hibernation temperature $\left(\mathrm{H}_{1,82}=1.176 \times 10^{-07}, \mathrm{P}=1\right)$ did not have a significant effect on the sum of DIO2-specific staining $\left(\mu \mathrm{m}^{2}\right)$ in the hypothalamus of male $T$. sirtalis (fig. 7). The duration of hibernation $\left(\mathrm{H}_{3,82}=15.785, \mathrm{P}=0.001\right)$ significantly affected the DIO2-stained area $\left(\mu \mathrm{m}^{2}\right)$ in the hypothalamus of males; animals had a larger sum of DIO2-ir staining $\left(\mu \mathrm{m}^{2}\right)$ with longer duration of hibernation. There was no significant effect of the interaction term on DIO2-stained area $\left(\mu \mathrm{m}^{2}\right)$ in the hypothalamus of male T. sirtalis $\left(\mathrm{H}_{3,82}=1.493, \mathrm{P}=0.684\right)$. 


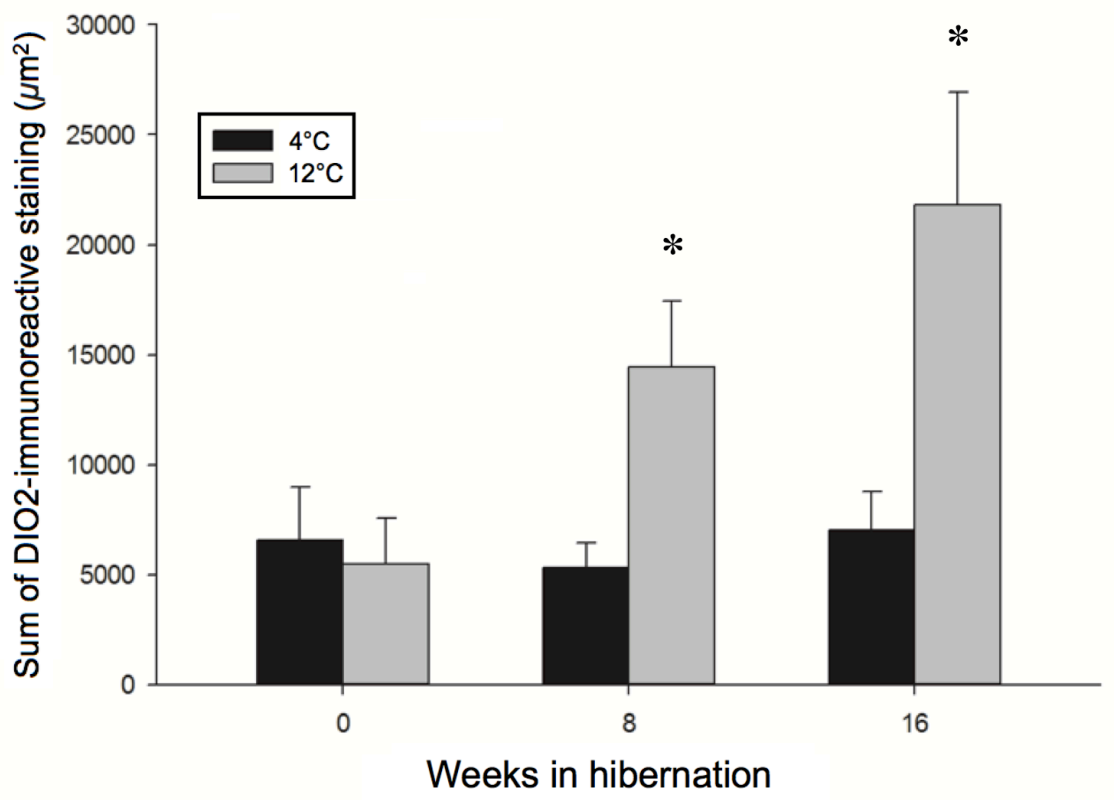

Figure 6. The sum of DIO2-specific staining in the hypothalamus of female T. sirtalis during hibernation at $4^{\circ} \mathrm{C}$ or $12^{\circ} \mathrm{C}$. Each bar is the mean $+1 \mathrm{SE}$. The sum of staining was greater in animals hibernated at $12^{\circ} \mathrm{C}$ than in animals hibernated at $4^{\circ} \mathrm{C}$. As expected, there was no difference between temperature groups at week $0(\mathrm{P}=0.874)$, but there was a significant difference between temperature groups at week $8(\mathrm{P}=0.016)$ and week $16(\mathrm{P}=0.005)$. Asterisks indicate significant differences between temperature groups within each sampling time.

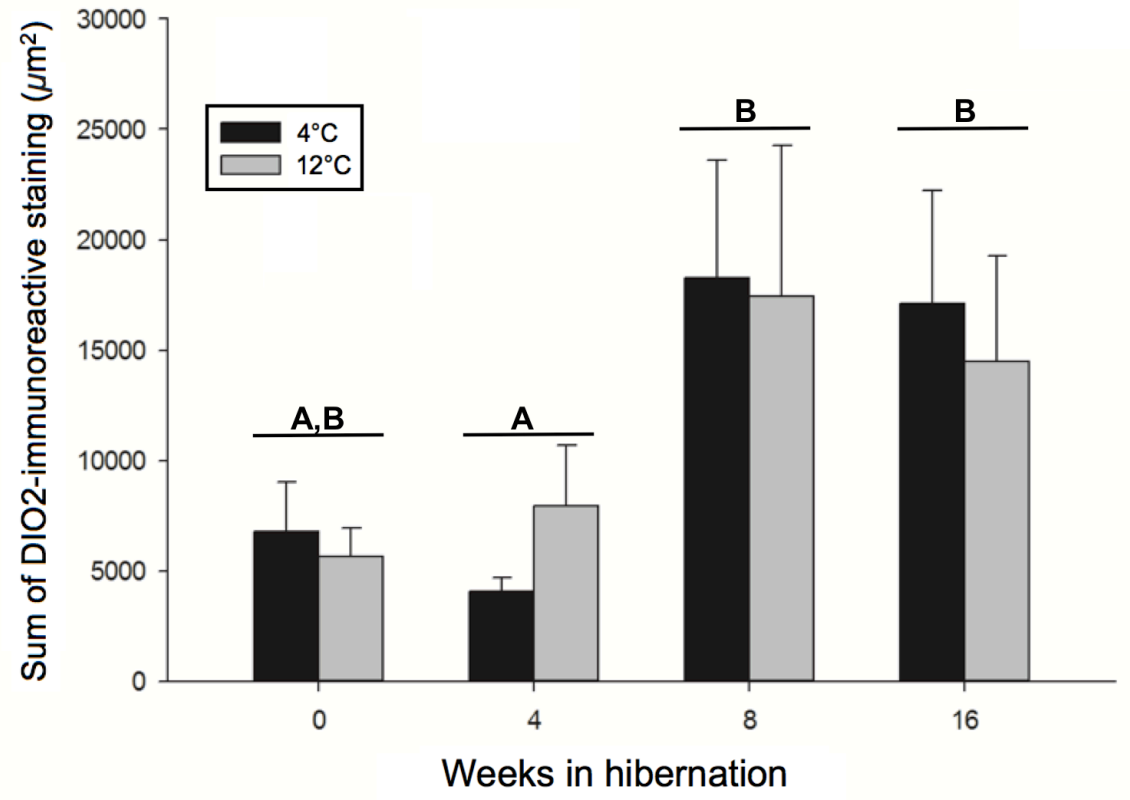

Figure 7. The sum of DIO2-specific staining in the hypothalamus of male Thamnophis sirtalis parietalis during hibernation at $4^{\circ} \mathrm{C}$ or $12^{\circ} \mathrm{C}$. Each bar is the mean $+1 \mathrm{SE}$. Duration of hibernation significantly affected the DIO2-stained area $\left(\mu \mathrm{m}^{2}\right)$ in the hypothalamus; animals had a larger sum of DIO2-ir staining $\left(\mu \mathrm{m}^{2}\right)$ with longer duration of hibernation. We found a significant difference between week 4 and week $8(\mathrm{P}<0.05)$ and between week 4 and week $16(\mathrm{P}<0.05)$. Letters indicate significant differences among sampling times. 


\section{Discussion}

The type 2 iodothyronine deiodinase, also known as deiodinase II (DIO2), is a selenoprotein that converts the relatively less-bioactive thyroid hormone thyroxine (T4) to its highly-bioactive counterpart triiodothyronine (T3). Increases in DIO2 expression or enzymatic activity lead to a higher rate of T4 conversion, resulting in a higher local concentration of T3 (Bechtold \& Loudon 2007, Köhrle, J. 1999). As thyroid hormones are used widely in the activation and regulation of physiological processes including metabolism (Furuya et al. 2010, Medina et al. 2011) as well as reproduction as previously discussed (Revel 2006, Watanabe et al., 2004, Yoshimura 2006, 2013), the mechanisms that regulate them are an interesting target for research with implications that go beyond the model system being studied.

We found DIO2-specific staining in the anterior hypothalamus, periventricular hypothalamic nucleus and ventral pre-optic area, along the longitudinally central region of the olfactory tract, in the bed nucleus of the stria terminalis, caudally in the cortex and optic tectum, and in the in the lateral septal nucleus. We found significant differences in the area of DIO2-specific staining in the anterior hypothalamus over time in both males and females, with DIO2-stained area increasing significantly between week 4 and week 8 in both $4^{\circ} \mathrm{C}$ and $12^{\circ} \mathrm{C}$ temperature groups in males, and DIO2-stained area increasing significantly at week 8 within the $12^{\circ} \mathrm{C}$ temperature group in females. There were no significant differences between temperature groups in males. 
Question 1: Is Deiodinase 2 in Thamnophis sirtalis parietalis affected by lowtemperature hibernation?

Our results demonstrate that DIO2 in the hypothalamus of red-sided garter snakes increases over time in response to low-temperature hibernation. This finding supports the hypothesis that the neuroendocrine pathway that regulates seasonal reproduction in birds, mammals, and fish is also shared in reptiles, bringing us considerably closer to confirmation that this is a conserved pathway in vertebrates.

In photoperiod-activated breeders, DIO2 increases in response to the day length leading to the season in which they breed; in other words, short-day breeders show elevated DIO2 in response to a shortened photoperiod, and long-day breeders show elevated DIO2 in response to an elongated photoperiod (Nakane \& Yoshimura, 2014). For example, among Djungarian, Siberian, and Syrian hamsters, all long-day breeders, DIO2 increases in response to exposure to a long photoperiod (Prendergast et al., 2013; Revel et al., 2006; Watanabe et al., 2004). Among shortday breeders such as the Saanen goat, DIO2 increases in response to a short photoperiod (Yasuo et al., 2006). Therefore, the increase in DIO2 seen in response to cool temperatures in $T$. sirtalis is consistent with what we would expect to find in a temperature-activated Spring breeder.

It is interesting that the increases we measured in DIO2-stained area are seen both at $4^{\circ} \mathrm{C}$ and at $12^{\circ} \mathrm{C}$ in male garter snakes, a temperature considerably higher than those typical during winter hibernation, when the temperature is likely to dip to below $1^{\circ} \mathrm{C}$ for sustained periods within the hibernaculum (Lutterschmidt et 
al., 2006). In the area of Manitoba where we collected our animals, $12^{\circ} \mathrm{C}$ would be typical of average mid-May or October daytime temperatures (NOAA website, n.d., accessed 2019). However, it is notable that the animals require a sustained duration of several weeks of consistently cool temperatures for the temperature to have an influence on DIO2, conditions which would normally only occur in their native region after mid-to-late October, when the snakes are in their underground hibernaculum.

Question 2: Is deiodinase II sensitive to the duration of low-temperature dormancy?

This research shows that in red-sided garter snakes, DIO2 increases over time in response to sustained exposure to temperatures at or below $12^{\circ} \mathrm{C}$. In order for this change to occur, it appears that these animals must be exposed to low temperatures for at least 4 weeks, leading to a rapid increase that is initiated between week 4 and week 8 , and then levels off between week 8 and week 16 . This indicates that there is a threshold effect for the duration of hibernation, in which snakes require a minimum time of exposure to reduced temperatures before the effects of the processes that induce DIO2 production are measurable. This is consistent with previous studies that have found that low-temperature hibernation is necessary to stimulate the onset of spring courtship behavior in male T. sirtalis (Gartska et al., 1982), but also that this onset was delayed after hibernation at $10^{\circ} \mathrm{C}$ as compared to $5^{\circ} \mathrm{C}$ (Lutterschmidt \& Mason, 2009). Further, there is preliminary research examining the relationship between courtship behavior and $\mathrm{GnRH}$, which 
found that GnRH-immunoreactive cell count and cell area were significantly increased at 8 weeks of low-temperature hibernation (Lutterschmidt et al. 2015).

Question 3: Are there sex differences in DIO2 in response to low-temperature hibernation?

In female T. sirtalis, deiodinase production increases over time in hibernation, and in contrast to our findings in males, it increases in animals that are hibernated at $12^{\circ} \mathrm{C}$, but not at $4^{\circ} \mathrm{C}$. One possibility is that the cool temperatures are necessary to activate the signaling pathway that results in production of DIO2, but metabolism is so slowed at $4^{\circ} \mathrm{C}$ that synthesis of proteins is inhibited. However, this seems unlikely, as we see increases during hibernation at $4^{\circ} \mathrm{C}$ in males, indicating that slowed metabolism alone is not responsible for this difference. An interesting question is why this large difference in DIO2 staining between temperature groups is seen in female T. sirtalis, while in males, there are no differences in DIO2-specific staining between temperature groups.

One possible explanation is sexual dimorphism in the use of DIO2 in this species. If males use the DIO2- $\mathrm{T}_{3}-\mathrm{GnRH}$ pathway to regulate courtship behavior, while females use it later in the season to regulate ovulation and/or fertilization, it could explain the differences seen here. Perhaps the majority of seasonal DIO2 production in females typically takes place when spring warming begins, after emergence, because females are using DIO2 to regulate reproductive processes that are temporally disconnected from spring emergence, courtship, and copulation. Reproductive activity in T. sirtalis is stimulated by cold-temperature hibernation. If 
females use some other temperature-sensitive mechanism to stimulate sexual receptivity during Spring emergence, they would not require production of DIO2 during hibernation. If increased DIO2 in females is linked to fertility, and fertilization occurs with stored sperm during the warmer late Spring and early Summer months, it would confer no benefit to a female snake to produce DIO2 and become fertile deep in winter. We know that sexually-attractive females are emerging from the den with body temperatures well below the $4^{\circ} \mathrm{C}$ (Lutterschmidt et al., 2006) that this research shows is too cold for an increase in DIO2 production to be taking place. This reinforces the likelihood that female attractivity and receptivity depend on different pathways, and perhaps different environmental cues, compared to male reproductive behavior.

It is plausible that DIO2 in the hypothalamus of female T. sirtalis increases when spring temperatures increase as a regulator of timing for vitellogenesis, ovulation, and ultimately, fertilization. These must be timed correctly for the birth of neonates to coincide, ideally, with the peak of the summer feeding season, to ensure their best chance of survival. It is worth noting that the $12^{\circ} \mathrm{C}$ group did not experience winter hibernation conditions, and we don't know if female T. sirtalis show an increase in hypothalamic DIO2 after Spring emergence, so this remains to be confirmed. Likewise, it is unknown if they show an increase in DIO2 during the Fall migration to the hibernaculum. If DIO2 stimulates vitellogenesis, an increase in DIO2 during the summer and/or Fall, prior to hibernation, could explain the finding that $80 \%$ of female $T$. sirtalis showed signs of vitellogenesis after low-temperature hibernation (Whittier et al., 1987). 
Because the experimental animals in the $12^{\circ} \mathrm{C}$ group did not experience the low temperatures required for this species to undergo reproductive activation, the females may not have become sexually receptive or even fertile; this leaves the door open for further exploration of the physiological functions that are activated by DIO2. For example, in animals that are cooled only to $12^{\circ} \mathrm{C}$, will we see vitellogenesis but no ovulation?

Experimental evidence has demonstrated that sexual attractiveness can be induced by hibernating female $T$. sirtalis at $4^{\circ} \mathrm{C}$ for at least 4 weeks and injecting them with estradiol (Crews et al., 1984, Lutterschmidt \& Mason 2009). It would be very interesting to determine whether this treatment also increases DIO2. It is established in this species that sexual receptivity and fertility are regulated separately (Crews et al., 1984), and it is interesting that we see an increase in DIO2 under mid-to-late Spring temperature conditions that would occur well before eventual fertilization will take place. As female T. sirtalis are able to store sperm to be used when their follicles mature later, and may become gravid a year or more after mating (Crews et al., 1984), perhaps DIO2 increases are a prerequisite for post-mating ovulation in female T. sirtalis. If so, it would make sense that DIO2 becomes elevated in response to a temperature that implies that the time to disperse to Summer feeding grounds has arrived. This timing may help ensure that gestation will occur over the summer, when a consistent food supply with which to nourish the developing fetuses is well-established.

Males undergo gametogenesis during the summer and store sperm over winter for Spring mating; they must be ready to deliver sperm immediately upon 
Spring emergence. While always harshly cold, northern Manitoba winters can vary in length, and male snakes have to hit the ground running, so to speak. If males use DIO2 to stimulate courtship behavior, it is in their best interest to start producing DIO2 as soon as they receive the signal that winter has commenced. This way, the male will be ready to court and deliver gametes to a receptive female as soon as spring thaw occurs, whether it occurs early or late in the season.

Most ectothermic vertebrates are capital breeders, relying on stored resources to support mating and the development of young (Bonnet et al., 1998.). Northern populations of $T$. sirtalis parietalis are no exception, and females in this population are also considered to be biennial breeders, alternating parturient and non-parturient years (Gregory 2006, Dayger et al., 2018). Although it is thought that only $50 \%$ of the females will reproduce in a given year, $80 \%$ of females hibernated for 7 weeks or more showed signs of vitellogenesis detected via palpation (Whittier et al. 1987). Photoperiod appears to have an effect on vitellogenesis, with unseasonably long photoperiod suppressing it, but not on sexual receptivity (Whittier et al. 1987). Light cues are not required to stimulate reproductive activity in T. sirtalis (Whittier et al., 1987), so we know there is a solely temperaturedependent component to reproductive activation in this species. Females may be using light cues alone or in combination with temperature cues to influence follicle development, but can use temperature alone to stimulate reproductive behavior.

Biennial reproduction may also provide an explanation for at least some of the variation observed in females in our experiment; if DIO2 is related to female reproductive condition, we would reasonably expect to see a great deal of variation 
in DIO2. Unfortunately, there is not yet a means in this species for determining which females will become parturient and which are post-parturient, though this ability would be extremely useful for researchers investigating reptile reproductive systems.

\section{Conclusion:}

This study was designed to answer the question of whether the reproductive regulatory pathway of temperature-activated seasonal breeders involves an increase in DIO2. Finding that the mechanisms of this endocrine pathway are shared between photoperiod-activated and temperature-activated seasonal breeders provides evidence that this is a conserved pathway that we can expect to find in most, if not all, vertebrates. Further, finding that this pathway is shared between photoperiod-activated seasonal breeders and temperature-activated seasonal breeders indicates that some animals may use both in conjunction with one another. This opens the door to the possibility that this pathway may be activated, moderated, or reinforced by other environmental cues as well, singly or in combination.

\section{Future directions and Broader Significance}

An interesting direction for future research would be to confirm that the other mechanisms of the seasonal reproductive regulatory pathway in a temperature-activated breeder are the same as those found in birds and mammals. In females of the European Starling, DIO2 and DIO3 have been found to work 
together to facilitate switching of the annual reproductive cycle in response to yet another environmental cue: social signals. The presence of a male causes female starlings to respond with increasing DIO2, acting as an "on" switch, and DIO3 acting as an "off" switch by deactivating T3 after DIO2 levels decline (Perfito et al., 2015). A similarly reciprocal relationship between DIO2 and DIO3 in a reptile model could elucidate whether this aspect of the pathway is shared across clades.

If these pathways modulating reproductive responses to environmental cues are indeed common among vertebrates, a more complete understanding of them will simplify identification of environmental cues used by other species. Urban light pollution is thought to be having a considerable deleterious effect on urban-adjacent wildlife populations by interfering with seasonal day-length cues in birds, sea turtles, and other vertebrates who mate or nest within visible range of city lights (Falchi et al., 2011; Gaston et al., 2013; Gaston et al., 2015; Longcore \& Rich, 2004). This could be confirmed if the mechanistic pathway posited here is found to be conserved in vertebrates. Confirmation of these mechanistic pathways could help inform research on the impacts of both light pollution and climate change on seasonal reproduction in countless affected species, and may also have hopeful implications for research aimed at increasing the success rate of artificial insemination in endangered animals. Agricultural applications along those lines are also a possibility.

Finally, and most intriguingly, knowledge of the pathways through which reproduction is regulated could have implications for human reproductive health; a disconnect or deficiency along the pathway may result in reduced fertility, or in a 
reproductive disorder such as Polycystic Ovarian Syndrome, that reduces the quality of life as well as the odds of conception for those affected by it. Knowledge of the involved neurohormonal mechanisms will be helpful for researchers developing treatments. Finally, one important emerging issue in public health is a pervasive sperm count decline in Western men, an estimated 58\% since the earliest data available in 1974 (Bonde \& Velde, 2017; Levine et al., 2017; Sengupta et al., 2018). Humans are weakly seasonal breeders, with birth rates that peak in late summer, between July and September in the US (Foster \& Roenneberg, 2008; Lam \& Miron, 1994), and this effect becomes more pronounced the more distant a population is from the equator (Brewis et al., 1996; Roenneberg \& Aschoff, 1990), which may imply that the effect is at least partially photoperiod-driven. A countering hypothesis is that cold temperatures keep people indoors in close proximity during midwinter, and that more conceptions occur during this time as a result, but existing research does not support this (Udry \& Morris, 1967) and it is insufficient to explain the marked increase in conceptions that begins in September, particularly in temperate regions where September is late summer, a peak harvest season. We have been very successfully filling our environment with increasing quantities of short-wavelength light, a very effective mimic of peak daylight. The research reported in this paper makes a novel contribution to a larger body of work examining the seasonal reproductive pathway in vertebrates. Taken all together, the body of work on vertebrate seasonal reproduction supports the biological plausibility that extended exposure to short-wavelength light could potentially be interfering with the human reproductive cycle, contributing to endocrine system 
disruption and, perhaps in combination with other environmental pollutants, leading to reduced sperm production. If this is the case, a thorough knowledge of these endocrine pathways and the environmental cues that influence them will be an important part of the puzzle in seeking solutions to this emerging human health problem. 


\section{Bibliography}

Ball, G. F., \& Ketterson, E. D. (2008). Sex differences in the response to environmental cues regulating seasonal reproduction in birds. Philosophical Transactions of the Royal Society of London B: Biological Sciences, 363(1490), 231-246.

Bechtold, D. A., \& Loudon, A. S. (2007). Hypothalamic thyroid hormones: mediators of seasonal physiology. Endocrinology, 148(8), 3605-3607.

Bonde, J. P., \& Te Velde, E. (2017). Male factor infertility: Declining sperm countsthe never-ending story. Nature Reviews Urology, 14(11), 645.

Bonnet, X., Bradshaw, D., \& Shine, R. (1998). Capital versus income breeding: an ectothermic perspective. Oikos, 333-342.

Brewis, A., Laycock, J., \& Huntsman, J. (1996). Birth non-seasonality on the Pacific equator. Current anthropology, 37(5), 842-851.

Bronson, F. H. (2009). Climate change and seasonal reproduction in mammals. Philosophical Transactions of the Royal Society B: Biological Sciences, 364(1534), 3331-3340.

Cho, R. N., Hahn, T. P., MacDougall-Shackleton, S., \& Ball, G. F. (1998). Seasonal variation in brain GnRH in free-living breeding and photorefractory house finches (Carpodacus mexicanus). General and comparative endocrinology, 109(2), 244-250.

Crews, D. (1984). Gamete production, sex hormone secretion, and mating behavior uncoupled. Hormones and behavior, 18(1), 22-28.

Dawson, A., King, V. M., Bentley, G. E., \& Ball, G. F. (2001). Photoperiodic control of seasonality in birds. Journal of biological rhythms, 16(4), 365-380.

Dayger, C. A., Lemaster, M. P., \& Lutterschmidt, D. I. (2018). Physiological correlates of reproductive decisions: Relationships among body condition, reproductive status, and the hypothalamus-pituitary-adrenal axis in a reptile. Hormones and behavior, 100, 1-11.

Deviche, P., \& Small, T. (2001). Photoperiodic control of seasonal reproduction: Neuroendocrine mechanisms and adaptation. Avian endocrinology, 113, 128.

de Miera, C. S., Monecke, S., Bartzen-Sprauer, J., Laran-Chich, M. P., Pévet, P., Hazlerigg, D. G., \& Simonneaux, V. (2014). A circannual clock drives expression of genes central for seasonal reproduction. Current Biology, 24(13), 1500-1506.

Duarte-Guterman, P., Navarro-Martín, L., \& Trudeau, V. L. (2014). Mechanisms of crosstalk between endocrine systems: regulation of sex steroid hormone synthesis and action by thyroid hormones. General and comparative endocrinology, 203, 69-85.

e Drigo, R. A., Fonseca, T. L., Werneck-de-Castro, J. P. S., \& Bianco, A. C. (2013). Role of the type 2 iodothyronine deiodinase (D2) in the control of thyroid hormone signaling. Biochimica et Biophysica Acta (BBA)-General Subjects, 1830(7), 3956-3964.

Foster, R. G., \& Roenneberg, T. (2008). Human responses to the geophysical daily, annual and lunar cycles. Current biology, 18(17), R784-R794. 
Furuya, F., Shimura, H., Yamashita, S., Endo, T., \& Kobayashi, T. (2010). Ligandedthyroid hormone receptor- $\alpha$ enhances proliferation of pancreatic $\beta$ cells. Journal of Biological Chemistry, jbc-M109.

Garstka, W. R., Camazine, B., \& Crews, D. (1982). Interactions of behavior and physiology during the annual reproductive cycle of the red-sided garter snake (Thamnophis sirtalis parietalis). Herpetologica, 104-123.

Gaston, K. J., Bennie, J., Davies, T. W., \& Hopkins, J. (2013). The ecological impacts of nighttime light pollution: a mechanistic appraisal. Biological reviews, 88(4), 912-927.

Gaston, K. J., Visser, M. E., \& Hölker, F. (2015). The biological impacts of artificial light at night: the research challenge.

Gregory, P. T. (2006). Influence of income and capital on reproduction in a viviparous snake: direct and indirect effects. Journal of Zoology, 270(3), 414419.

Kirschbaum, F. (1987). Reproduction and development of the weakly electric fish, Pollimyrus isidori (Mormyridae, Teleostei) in captivity. Environmental Biology of Fishes, 20(1), 11-31.

Köhrle, J. (1999). Local activation and inactivation of thyroid hormones: the deiodinase family. Molecular and cellular endocrinology, 151(1), 103-119.

Lam, D. A., \& Miron, J. A. (1994). Global Patterns of Seasonal Variation in Human Fertility. Annals of the New York Academy of Sciences, 709(1), 9-28.

Levine, H., Jørgensen, N., Martino-Andrade, A., Mendiola, J., Weksler-Derri, D., Mindlis, I., Pinotti, R., \& Swan, S. H. (2017). Temporal trends in sperm count: a systematic review and meta-regression analysis. Human Reproduction Update, 23(6), 646-659.

Lewis, J. E., \& Ebling, F. J. (2017). Tanycytes as regulators of seasonal cycles in neuroendocrine function. Frontiers in neurology, 8, 79.

Licht, P. (1972). Environmental physiology of reptilian breeding cycles: role of temperature. General and comparative endocrinology, 3, 477-488.

Longcore, T., \& Rich, C. (2004). Ecological light pollution. Frontiers in Ecology and the Environment, 2(4), 191-198.

Lutterschmidt, D. I., LeMaster, M. P., \& Mason, R. T. (2006). Minimal overwintering temperatures of red-sided garter snakes (Thamnophis sirtalis parietalis): a possible cue for emergence?. Canadian Journal of Zoology, 84(5), 771-777.

Lutterschmidt, D.I., A.R. Lucas, and A.R. Summers. 2015. Trans-seasonal activation of brain GnRH: Mechanisms underlying temperature-induced reproduction. Society for Integrative and Comparative Biology. West Palm Beach, Florida.

Lutterschmidt, D. I., \& Maine, A. R. (2014). Sex or candy? Neuroendocrine regulation of the seasonal transition from courtship to feeding behavior in male redsided garter snakes (Thamnophis sirtalis parietalis). Hormones and behavior, 66(1), 120-134.

Lutterschmidt, D. I., \& Mason, R. T. (2009). Endocrine mechanisms mediating temperature-induced reproductive behavior in red-sided garter snakes (Thamnophis sirtalis parietalis). Journal of Experimental Biology, 212(19), 3108-3118. 
MacDougall-Shackleton, S. A., Deviche, P. J., Crain, R. D., Ball, G. F., \& Hahn, T. P. (2001). Seasonal changes in brain GnRH immunoreactivity and song-control nuclei volumes in an opportunistically breeding songbird. Brain, behavior and evolution, 58(1), 38-48.

Maclean, I. M., \& Wilson, R. J. (2011). Recent ecological responses to climate change support predictions of high extinction risk. Proceedings of the National Academy of Sciences, 108(30), 12337-12342

Maine, A. R., Powers, S. D., \& Lutterschmidt, D. I. (2014). Seasonal variation in cell proliferation and cell migration in the brain of adult red-sided garter snakes (Thamnophis sirtalis parietalis). Brain, behavior and evolution, 84(3), 181196.

Nakane, Y., Ikegami, K., Iigo, M., Ono, H., Takeda, K., Takahashi, D., Uesaka, M., Kimijima, M., Hashimoto, R., Arai, N., Suga, T., Kosuge, K., Abe, T., Maeda, R., Senga, T., Amiya, N., Azuma, T., Amano, M., Abe, H., Yamamoto, N., \& Yoshimura, T. (2013). The saccus vasculosus of fish is a sensor of seasonal changes in day length. Nature communications, 4, 2108.

Nakane, Y., \& Yoshimura, T. (2014). Universality and diversity in the signal transduction pathway that regulates seasonal reproduction in vertebrates. Frontiers in neuroscience, $8,115$.

NOAA Baseline Climatological Dataset - Monthly Weather Station Temperature and Precipitation Data. (n.d.). Retrieved from http://iridl.ldeo.columbia.edu/SOURCES/.NOAA/.NCDC/.GCPS/.MONTHLY/. STATION/.dataset_documentation.html

Perfito, N., Guardado, D., Williams, T. D., \& Bentley, G. E. (2014). Social cues regulate reciprocal switching of hypothalamic Dio2/Dio3 and the transition into final follicle maturation in European starlings (Sturnus vulgaris). Endocrinology, 156(2), 694-706.

Prendergast, B. J., Pyter, L. M., Kampf-Lassin, A., Patel, P. N., \& Stevenson, T. J. (2013). Rapid induction of hypothalamic iodothyronine deiodinase expression by photoperiod and melatonin in juvenile Siberian hamsters (Phodopus sungorus). Endocrinology, 154(2), 831-841.

Revel, F. G., Saboureau, M., Pévet, P., Mikkelsen, J. D., \& Simonneaux, V. (2006). Melatonin regulates type 2 deiodinase gene expression in the Syrian hamster. Endocrinology, 147(10), 4680-4687.

Roenneberg, T., \& Aschoff, J. (1990). Annual rhythm of human reproduction: II. Environmental correlations. Journal of Biological Rhythms, 5(3), 217-239.

Sengupta, P., Borges Jr, E., Dutta, S., \& Krajewska-Kulak, E. (2018). Decline in sperm count in European men during the past 50 years. Human \& experimental toxicology, 37(3), 247-255.

Udry, J. R., \& Morris, N. M. (1967). Seasonality of coitus and seasonality of birth. Demography, 4(2), 673-679.

Watanabe, M., Yasuo, S., Watanabe, T., Yamamura, T., Nakao, N., Ebihara, S., \& Yoshimura, T. (2004). Photoperiodic regulation of type 2 deiodinase gene in Djungarian hamster: possible homologies between avian and mammalian photoperiodic regulation of reproduction. Endocrinology, 145(4), 1546-1549. 
Whittier, J. M., Mason, R. T., Crews, D., \& Licht, P. (1987). Role of light and temperature in the regulation of reproduction in the red-sided garter snake, Thamnophis sirtalis parietalis. Canadian journal of zoology, 65(8), 20902096.

Yasuo, S., Nakao, N., Ohkura, S., Iigo, M., Hagiwara, S., Goto, Ando, H., Yamamura, T., Watanabe, M., Watanabe, T., Oda, S., Maeda, K., Lincoln, G., Okamura, H., Ebihara, S., \& Yoshimura, T.(2006). Long-day suppressed expression of type 2 deiodinase gene in the mediobasal hypothalamus of the Saanen goat, a short-day breeder: implication for seasonal window of thyroid hormone action on reproductive neuroendocrine axis. Endocrinology, 147(1), 432-440.

Yoshimura, T. (2006). Molecular mechanism of the photoperiodic response of gonads in birds and mammals. Comparative Biochemistry and Physiology Part A: Molecular \& Integrative Physiology, 144(3), 345-350.

Yoshimura, T. (2013). Thyroid hormone and seasonal regulation of reproduction. Frontiers in neuroendocrinology, 34(3), 157-166. 